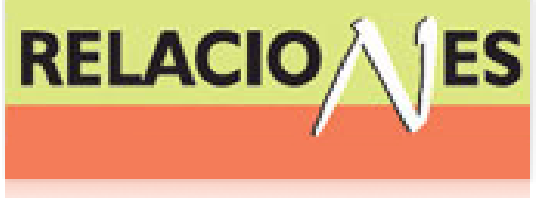

Relaciones. Estudios de historia y sociedad ISSN: 0185-3929

relacion@colmich.edu.mx

El Colegio de Michoacán, A.C

México

Torres, Gabriel

La hummerización: "desorden" local, diversidad cultural y dominación policéntrica en el medio rural mexicano

Relaciones. Estudios de historia y sociedad, vol. XXXIII, núm. 132, 2012, pp. 223-262

El Colegio de Michoacán, A.C

Zamora, México

Disponible en: http://www.redalyc.org/articulo.oa?id=13725799008

- Cómo citar el artículo

- Número completo

- Más información del artículo

- Página de la revista en redalyc.org

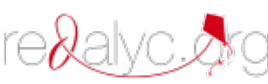

Sistema de Información Científica

Red de Revistas Científicas de América Latina, el Caribe, España y Portugal Proyecto académico sin fines de lucro, desarrollado bajo la iniciativa de acceso abierto 


\title{
La hummerización: "desorden" local, diversidad cultural y dominación policéntrica en el medio rural mexicano
}

\author{
Gabriel Torres*
}

CIESAS-OCCIDENTE

Este artículo identifica los patrones de comportamiento del régimen de dominación global/local específico en sus efectos hacia el medio rural mexicano. Las formas de "dominación neoimperialista" de corte estructural, son vistas desde lo local y se revisan críticamente en términos económicos, políticos, tecnoinformáticos y sociales. Esa perspectiva se concreta con el uso de la metáfora de la "hummerización", la cual sirve para subrayar la ambivalencia del poder neoimperial. Esa ambivalencia es análoga a la que se presentó con el uso de los vehículos hummer, de fugaz relevancia social debido al dispendioso uso de combustible que requieren.

El análisis etnográfico se centra en un estudio de caso localizado en la costa jalisciense que se observa desde dos enfoques distintos. Un enfoque situacional integrado a partir de entrevistas y observaciones indirectas en torno a un fenómeno extraordinario: la extraña muerte de una madre joven de 26 años quien fue quemada viva en su propia casa. El otro enfoque es de corte histórico estructural y recoge la memoria personal del autor haciendo uso de apuntes de distintas épocas, recopilados desde la condición de testigo de la vida comunitaria local y con una visión extendida hacia lo regional/nacional que abre la perspectiva de seguimiento a las cuatro últimas décadas.

(Hummerización, dominación policéntrica, diversidad cultural)

*1torres@cencar.udg.mx El substrato originario de este documento, se presentó como ponencia al foro Translocalidad: Diálogos sobre la cultura y el cambio en el siglo xxi. Dicho foro formaba parte de la sesión plenaria Anthropology Confronting Empire presidida por Marie France Labrecque como parte de los trabajos del Congreso organizado por The Canadian Anthropology Society, The Society for the Anthropology of North America y la Facultad de Ciencias Antropológicas de la Universidad Autónoma de Yucatán, en el mes de mayo del 2005. El congreso fue coordinado localmente por Steffan Igor Ayora-Díaz y Gabriela Vargas-Cétina quienes me invitaron a participar en dicho foro. La 
INTRODUCCIÓN: EL SENTIDO TEÓRICO DE LA ETNOGRAFÍA LOCALIZADA

ste artículo explora el potencial explicativo del análisis etnográfico de la vida cotidiana en el sentido previsto por Raymond Williams quien concibe la cultura y sus representaciones como "formaciones de lo ordinario y expresiones de la totalidad de los modos de vida". ${ }^{1}$ Este uso coincide con el propuesto por Paul Willis. ${ }^{2}$ En mi caso, usaré las descripciones etnográficas para advertir sobre la manera mecánica como se han aplicado conceptos globales en el caso del neoimperio y la idea de multitud ofrecidos por Hardt y Negri.

Mi reflexión se enfoca en lo planteado por Kapferer quien sugiere "atender empíricamente la diversidad de estructuras sociales involucradas o emergentes en el contexto del Imperio" (2002, 274). En las descripciones de realidad que analizo, he logrado confirmar en muchos sentidos el gran potencial para la oposición y resistencia imaginado por Hardt y Negri "que no se había desarrollado en otros regímenes políticos modernos" (2004, 393). Sin embargo, la gran diferencia que tengo con ellos, estriba en la intensidad y discontinuidades que percibo en los procesos sociales, los cuáles aunque por momentos se presentan como circunstancias de violencia extrema y resistencia persistente, luego prevalecen discontinuidades, diversas expresiones de desobediencia y aisladas formas de insurrección social. Eso obliga a observar la heterogeneidad de las situaciones y verlas con una diversidad de significados e intereses propios de las conductas de las multitudes. En ese sentido, aunque logran hacer menos efectivos los sistemas de control y desnudan el carácter coyuntural de la estrategia de dominación, ello no significa que automáticamente tengan que interpretarse como procesos sumatorios de una escalada revolucionaria.

Kapferer sugiere proceder con caracterizaciones matizadas de procesos sociales y dinámicas estructurales. Su sugerencia me parece

discusión giró en torno a dos textos centrales de Michael Hardt y Antonio Negri, Empire, Harvard University Press, 2002 y Multitude, Penguin Books, 2004.

${ }^{1}$ Para más detalle véase el libro de Raymond Williams, The Long Revolution, 2003, 105.

${ }^{2}$ Paul Willis, The Etnhographic Imagination, 2000. 
pertinente para analizar el caso complejo del medio rural mexicano donde se ha pasado por varias involuciones que transformaron la presencia del Estado mexicano y la relación de subordinación de los campesinos hacia el gobierno en el transcurso de unas cuantas décadas. Con esa precaución, intento caracterizar la lógica neoimperial con sus matices pragmáticos y sobre todo con sus sesgos ideológicos.

En este contexto, identificaré los patrones de comportamiento del régimen de dominación global/local específico, para luego abrir el horizonte hacia las formas de "dominación neoimperialista" de corte estructural, proyectadas desde lo local y expresadas en términos económicos, políticos, tecnoinformáticos y sociales. Esa perspectiva, la trato de concretar con el uso de la metáfora de la "hummerización" de la sociedad, la cual me sirve para subrayar la ambivalencia del poder neoimperial. Como sucede con un mega-poder cuando se somete al desgaste de distintas situaciones de la vida cotidiana, termina por no funcionar y de hecho enfrenta múltiples circunstancias en las que es inoperante, se le ignora a pesar de su aparato y ventajas tecnológicas, de su maquinaria de guerra y de su aparato de control ideológico y de sus estrategias de intimidación. Eso es parecido, a lo que le ha pasado al ejército de Estados Unidos en Irak y en otros países asiáticos. Cierto, podrán resultar vencedores y hacer muchos atropellos y masacres que reflejan una doble cara de la dominación y, por ello, no se libran de la obsolescencia y presencia de corta duración, así como de otras limitaciones que caracterizan ese tipo de dominación imperial. Esa ambivalencia la he reflejado de forma análoga a la que se presenta con el uso de los vehículos hummer, de fugaz relevancia social debido al dispendioso uso de combustible que requieren.

El análisis etnográfico se centra en un estudio de caso localizado en la costa jalisciense que se observa desde dos enfoques distintos. Un enfoque situacional integrado a partir de entrevistas y observaciones indirectas en torno a un fenómeno extraordinario, mientras que el histórico estructural recoge la memoria personal y apuntes de distintas épocas, realizados desde la condición de testigo de la vida comunitaria local y una visión extendida hacia lo regional/nacional que abre la perspectiva de seguimiento a las cuatro últimas décadas. 
La etnografía resalta los indicios del retorno del tribalismo ${ }^{3}$ como agente social característico de la representación de "multitud" en un espacio del tercer mundo concebido a lo Maffesoli (2004). Se trata de espacios con muchos intersticios en las relaciones sociales locales que aparecen permeadas por apariencias de "desorden", diferencias culturales profundas y situaciones cambiantes. Esos indicios no se agotan en lo local, porque también aparecen conectados y hasta dominados por la cultura global, claro, en medio de avances y retrocesos con ricas representaciones de diversidad cultural (Gupta y Ferguson 1999). Lo relevante es observar porque esas localidades no cuadran, ni terminan por alinearse.

Mi manera de entender la localidad, coincide con el uso de Appadurai $(1998,178)$ quien la percibe como inserta en una condición más relacional y contextual, no tanto de escala espacial. En las narrativas etnográficas, la localidad es el escenario donde se juegan interrelaciones sociales globales y locales, pero muy entremezcladas culturalmente puesto que operan sin un plan predeterminado, eso lo hago en el sentido propuesto por Renato Rosaldo quien parafrasea a Marx cuando señala: "la gente crea sus propias historias, pero bajo condiciones que ellos no escogen y con consecuencias que no planearon" $(1991,102)$.

El artículo se divide en tres partes. En la primera, se hace un análisis situacional del comportamiento comunitario ante el "fenómeno inexplicado" de la muerte de María Gutiérrez una joven madre de escasos 26 ańos. El análisis se dirige a explicar la actitud de "ignorancia comunitaria" y la diversidad de significados que los actores de la comunidad atribuyeron a esa desaparición. La segunda parte, hace un recuento histórico del poblado donde vivía María

${ }^{3}$ La metáfora de Maffesoli más que subrayar "el desorden”, lo primitivo o rudimentario del proceso social, pretende indicar lo mítico de la modernización y el progreso. Las grandes instituciones (Iglesia y Estado) están inmersas en constantes luchas por la relevancia y el control de la vida social. En muchas circunstancias, se puede observar que ya no son las grandes instituciones las que prevalecen sino varias pequeñas entidades que emergen y dan sentido a la cotidianidad, de ahí la apuesta por el policentrismo que en este sentido es convergente con la visión de Hardt y Negri. En el tribalismo se simboliza el reagrupamiento de los miembros de una comunidad específica para enfrentar diversas adversidades. $(2004,10)$ 
con dos propósitos: 1) completar los vacíos de información necesarios para comprender el contexto de la situación analizada previamente, y 2) identificar las etapas y pautas del proceso de desarrollo de ese ejido en sus horizontes más amplios. En la tercera parte, se contradicen los dos extremos de la lógica neoimperial: el de la dominación vía medios (uso potencializado y mitificado del internet) y el de la revolución facilitada concebida por Hardt y Negri. Como una tercera vía ante ese dualismo, se propone tomar en serio la idea de la diversidad cultural como medio para entender las diferencias inscritas en las formas de dominación policéntricas.

\section{El disCurso del Nuevo IMperio: SUS AMbiciones Y SUS LÍMITES}

En México como en otras partes del mundo, a partir del 2006, se generalizó el uso de los vehículos "hummer". ${ }^{4}$ El hummer como medio de transporte individual y familiar, refleja una sobredimensionada necesidad de seguridad asociada a imágenes de poder que suponen ventajas para quien posee y conduce ese vehículo. ${ }^{5}$ De hecho, se promociona como un auto fuerte que puede llegar a cualquier parte.

${ }^{4}$ La idea de la hummerización de la sociedad, sirve para caracterizar la situación postguerra del desierto y la prematura decadencia neoimperial que no logró perdurar ni siquiera una década y que significa un retroceso de ideas mayormente impactado por la triple crisis: económica, ambiental y social. Este uso conceptual, es similar al de la macdonalización de la sociedad empleado por Georges Ritzer (1996) a mediados de los noventa que sirvió para identificar esa época, como un estilo peculiar de desarrollo capitalista que interrelacionaba flujos económico-sociales, global-locales, centrados en el consumo de la comida rápida (fast food). La hummerización en esta coyuntura, subraya el ambiente guerrerista contra el terrorismo que se desencadenó tras el fenómeno del 11 de septiembre del 2001. Cabe señalar, que el hummer al pasar de un vehículo de guerra a un todo terreno, proyecta un mensaje simbólico.

${ }^{5}$ La proliferación del hummer se difunde mediante estrategias mercantiles de alta exclusividad ("like nothing else" como "nada igual en el mundo") y busca proyectar un estilo de vida para usuarios de elite a quienes se les hace sentir que no se detendrán ante ningún obstáculo (www.hummermexico.com.mx). Bajo ese tipo de propaganda, el manejar un hummer representaba algo de mucha altura, que servía para motivar a los estudiantes destacados como en el caso de la Universidad de York en Toronto, quienes obtendrían como premio el privilegio de darse una vuelta alrededor del campus universitario en un hummer (Comunicación personal Dra. Barndt profesora de la facultad de estudios ambientales. Enero 8, 2009). 
Pero, desde otra óptica, se trata de un vehículo muy obeso e incomodo para estacionarlo en espacios estrechos del ámbito urbano, donde irónicamente es donde más se ha vendido. La observación de ese carácter contradictorio (mucho poder pero también inutilidad práctica) me sirve para hablar del carácter decadente del discurso de poder neoimperial y su representación en escenarios localizados.

En México, los hummer adquirieron una mayor notoriedad política, tras la compra masiva realizada en el mes de septiembre de 2008, por parte del Sindicato Nacional de Trabajadores de la Educación (sNTE) y su lideresa: Elba Esther Gordillo, quien pretendía de esa forma, agregar privilegios en favor de los líderes de las distintas secciones del sindicato de maestros, bajo el supuesto de equiparlos con vehículos que los llevaran a cualquier localidad de sus zonas de trabajo. ${ }^{6}$ La crisis económica desatada, desnudó muy pronto que se trataba de un acto de ostentación desmedido, por lo que se abandonó la idea original de repartirlos a los dirigentes. Para paliar el descrédito, los rifaron con otro nuevo pretexto de obtener recursos para algunas escuelas pobres. ${ }^{7}$

La reinvención del hummer como auto de uso civil, está asociada al relanzamiento de la industria militar como sector de punta y al predominio de las ideas neoimperialistas. En consonancia con el

${ }^{6}$ Esta circunstancia hay que tomarla como uno más de los efectos políticos que se derivan de la alianza de poder que facilitó el acceso al gobierno del equipo del presidente Calderón. Como es sabido, en el año del 2006 ocurrieron las elecciones más competidas de México. La posibilidad de ganar la elección para el pan y Felipe Calderón se selló con el apoyo de personajes como la maestra Elba Esther Gordillo y el sindicato de maestros que se ostenta como el más numeroso de América Latina. De ser secretaria general del PRI, Gordillo pasó a la disidencia priísta y se convirtió en fundadora y promotora del partido Nueva Alianza, una organización política de fachada del sindicato de maestros que cada vez más evidencia su carácter de comparsa y afinidad con los intereses del grupo gobernante. La red de políticos expriístas que atrajo Elba Esther y el SNTE representaron un factor clave que por las buenas y por las malas, obtuvo el porcentaje de votos necesarios para inclinar la balanza a favor del grupo calderonista. Como parte de los acuerdos y la vuelta de favores, el SNTE y esa red de políticos expriístas han sido privilegiados con posiciones en varios niveles del gobierno (ISSTE y Lotería Nacional), así como prebendas especiales y un presupuesto a modo. La compra de los hummers es un reflejo de esa cohabitación en el poder.

${ }^{7}$ Cfr. Periódico El Universal, domingo 12 de octubre de 2008 p. 1 A y Excelsior 13 de octubre 2008. 
discurso guerrerista, andar en un hummer por las calles donde transitan ciudadanos comunes y corrientes, equivale a deambular por las sendas de un imaginario de ciencia ficción, tipo "guerra de las galaxias" donde se acostumbran espectaculares avances tecnológicos: centros de mando, aparatos de comunicación con rastreo satelital y otras ventajas militares. ${ }^{8}$

La retórica neoimperial, en la perspectiva contemplada por Hardt y Negri es una representación de poder global que exalta la capacidad de intervenir y dominar en cualquier parte del mundo sólo por disponer de ventajas militares. Al neoimperio, le gustan las intervenciones expeditas que difícilmente cumplen con las regulaciones internacionales como ha sucedido en Irak, Afganistán y Pakistan.

El libreto es muy simple. Primero hay que tener enemigos bien identificados: bandas terroristas, Al Qaeda, talibanes, dictadores como Hussein o Ghadafi. Países que puedan cuadrar entre los del "eje del mal": Irak, Corea del Norte e Irán. El otro trámite, es imponer la intervención armada arguyendo factores estratégicos, defensivos o humanitarios, pero sobre todo lo que permita velar el ejercicio de poder que facilite mantener aceitada la maquinaria de guerra, mostrar el músculo y que demuestre la capacidad de progreso tecnológico. Irónicamente otro pretexto invocado puede ser la ética, los derechos humanos, la democracia y la sobrevivencia de la humanidad. Finalmente, todo resulta ser pragmatismo puro, que evidencia conveniencias circunstanciales como el apropiarse o cuidar de yacimientos petroleros.

Lo anterior, nos permite identificar el perfil previsto para este nuevo imperialismo por Harvey (2003). En primer término, ofrecer una cara moderna respecto del oligopolio imperialista que Lenin caracterizó hacia el año de 1917, como la fase superior del capitalismo. Harvey lo llama neomonopolio de las artes de guerra, que ha acabado con el mundo de la libre competencia guerrera como en otro tiempo lo hicieron los carteles capitalistas decimonónicos que Lenin identificaba $(1920,87)$, eso termina por acentuar la agresividad intervencionista como factor central para el reparto del mundo entre las potencias.

${ }^{8}$ Cfr. Reportajes televisivos de CNN en tiempos de la invasión a Afganistán e Irak. 
Desde el punto de vista de Harvey, la lógica neoimperial trasciende la institucionalidad Estado-nación y se construye socialmente como una articulación trasnacional que interconecta varias entidades postindustriales (que en realidad operan como unidades desincorporadas de grandes trust y series de maquiladoras con entidades productivas distribuidas en muchos países que funcionan con mayor refinamiento y discrecionalidad). El control de la producción de esa maquinaria de guerra queda en manos de grupos privados super discretos que deciden y actúan más allá de los intereses de una diversidad de naciones y funcionan como aparatos y recursos económicos postnacionales.

Ya se sabía que el espíritu capitalista per se, conducía a una lógica de expansión y control territorial. La novedad del neoimperialismo (Harvey 2003, 33) consiste en proyectar los horizontes de una expansión sin barreras. Eso significa encontrar la forma de operar en un mundo permanentemente abierto, que dé facilidades para satisfacer las ansias de poder de grupos muy selectos que manejan las patentes de guerra y la tecnología de punta. En la retórica de George Bush, el enfoque de seguridad nacional con todo y muros fronterizos funcionaba como cortina de humo.

Hay otra forma distinta pero convergente de entender esa lógica, como lo hacen Hardt y Negri. Ellos hablan de una pretensión metahistórica que busca borrar todo límite temporal para lograr una "totalidad espacial” con una soberanía ilimitada que corresponde con el objetivo de dominar sobre todo el mundo civilizado (2000, xiv).

Esa idea de "imperio" que proponen Hardt y Negri, tiene un desarrollo subsecuente en la noción de multitud, considerada ésta como el producto de ese reinado. La idea de multitud permite trascender empantanamientos entre la subjetividad y la comunalidad al proyectar espacios y acciones políticas que trascienden los contextos del Estado-nación y se inscriben en el orden jurídico internacional.

Esa visión reproduce un dualismo al ver en las multitudes un espectro blanco y negro, ya sea porque se les considere como entidades protagónicas capaces de actuar en un cuerpo común que forma parte de una escalada o ciclo de luchas globales creativas y positivas, o en otro extremo, al verlas como entidades pasivas y hasta amorfas 
que como vampiros o monstruos tienen una conducta que no es en ningún sentido vaticinable. Hardt y Negri reiteran la creencia que ve en las multitudes la posibilidad del surgimiento de un nuevo poder que se está inoculando (Hardt y Negri 2004, 194). En consonancia, plantean la idea del ciclo de luchas globales acumuladas, en las que la multitud se sujeta a otra disyuntiva dualista: vivir sujeta a las condiciones de manipulación y deseos del imperio o resistirse y luchar por su soberanía rompiendo totalmente los lazos de control. Hay que observar que las multitudes no se pueden reducir a su carácter de consumidores, pero tampoco cabe encuadrarlas en el romanticismo que identifica alternativas e insurrecciones de corte unitario en cualquier localidad.

\section{La “EXtraña MUerte” de María9}

Los zumbidos y la tronadera producida por el fuego en cada ocasión que se reavivaba, la densa humareda negra y el ruido persistente de la alarma de la camioneta que se mantuvo activada por más de media hora, se constituyeron en los indicios más relevantes del desastre familiar que afectaba a los Gutiérrez. El incendio de su "casa vieja"10 había convertido al poblado de El Porvenir en la costa de Jalisco, en un infierno chiquito que hacía sentir en forma más intensa el calor extremo y las condiciones de canícula al inicio de esa noche del mes de mayo. ${ }^{11}$

${ }^{9}$ Dada la condición fatal de los sucesos narrados, se usan seudónimos y una referencia general al poblado que tiene un nombre distinto con el fin de preservar la identidad de las personas entrevistadas y los sujetos que intervienen en la narrativa etnográfica.

${ }^{10}$ En la manera de operar de esta comunidad de migrantes, primero se construía una casa provisional que en la mayoría de casos se ubicaba a un lado o en la parte posterior del lote urbano del poblado fundado hacia fines de los setenta. Cada lote medía 600 metros cuadrados, espacio suficiente para desarrollar la vivienda, con huerto y traspatio.

${ }^{11}$ Ese ambiente de tensión nocturna es bien descrito en la narrativa de Hermenegildo Holguín, reportero del periódico Diez que apareció en el núm. 95 del 19 de julio de 1983. Holguín describe lo que vivió en una noche en ese poblado en los siguientes términos: "aquí y allá se empezaron a prender lucecitas en las casas [...] se oía ladrar unos peros y todavía más lejos las voces inaudibles de muchas gentes [...] apenas empezaba a acomodarme para dormir, cuando me avisaron de un altercado a varias cuadras [...] la noche estaba cerrada [...] y el calor era pegajoso, duro y lleno de moscos [...] horas des- 
Como lo relata una vecina y confidente de la familia:

eran como las ocho de la noche, cuando vino un compadre a decirme que se estaba quemando la casa de enfrente y que había que hacer algo. Me salgo a la carrera y veo la llamarada que crecía y que estaba devorando la casa de madera. Le pregunto ¿compadre: pero que está pasando? Me respondió se está quemando la casa y ellos (los Gutiérrez que estaban sentados afuera de la casa) dicen que no pasa nada. Como puede ser posible, le contesto. En esas estábamos, cuando escuchamos que el agente municipal se acercó a preguntar si en algo lo necesitaban y que estaba dispuesto a apoyarlos y ellos le dijeron que no era necesario (Entrevista 1).

Una vez que se consumieron todos los objetos encerrados en la casa, los colchones, las sillas, la ropa y otros enseres distinguibles entre las cenizas, el incendio pareció apaciguarse, pero ya estaba cerca el amanecer. El recuerdo de ese incendio quedaría grabado en la memoria de esa comunidad ejidal compuesta por 120 familias, como una "noche de brujas". Los vecinos desistieron de ayudar, ante la aparente resignación de los Gutiérrez, quienes sabían lo que pasaba y se declararon vencidos ante la fatalidad de las pérdidas irreparables. Luego se supo que ellos dijeron estar esperanzados de que algo bueno surgiría después del incendio, como se los había prometido el curandero de hechizos en quien confiaron. En efecto, los Gutiérrez cumplieron al pie de la letra la instrucción del curandero: "para que ella quede bien sana, van a necesitar quemar la casa con todo lo que tengan ustedes y ella estando dentro del cuarto. Al otro día, ella va a salir sonriente como siempre ha sido" (Entrevista 2).

Los Gutiérrez esperaban ver ese resultado, luego de que habían intentado en vano lograr el alivio de su hija enferma. María era recordada por sus compañeras de escuela, como muy alegre. Era la hija mayor de la familia y tenía 3 hijos incluyendo el más pequeño de apenas 2 meses. Su hija mayor tenía 6 años. Esa noche su esposo se

pués supe que del altercado había resultado un herido con arma blanca y de allí se ocasionó el allanamiento de una casa; golpearon a dos personas que nada tenían que ver y sin orden de aprehensión unos judiciales auxiliados por policías municipales se llevaron a un muchacho". 
llevó a sus 3 hijos a otra casa, a petición de sus suegros. María se había enfermado desde hacía dos años y sus padres estaban gastando mucho para curarla. Aparentemente, se desesperaron porque no mejoraba, a pesar de que la habían llevado a consulta con varios médicos y que había estado internada en el seguro social de Puerto Vallarta por más de 6 días. Su enfermedad se manifestaba con borracheras y temperaturas muy altas, pero los médicos decían que no le encontraban nada anormal, además que era muy joven. María tuvo un momento de mejoría cuando el señor cura le había hecho un exorcismo que la hizo ver alegre y sonriente por algunos días, "luego de que arrojó algo verde y dijo cosas que nadie le entendía” (Entrevista 1).

Por eso, se creyó que estaba hechizada. ${ }^{12}$ En el caso de María su hechizo se relacionaba con el vicio que había agarrado de jugar a la güija, al grado de descuidar a sus hijos. María jugaba a la güija con 3 amigas, desde que se fue a vivir a la cabecera municipal y se juntó con su novio sin permiso de sus padres. Para regresar a su casa paterna, tuvo que humillarse y pedir perdón. Pero, en una ocasión, se fue a Guadalajara a jugar a la güija. De plano, estaba "empicada”, según explicaron sus compañeras de escuela. ${ }^{13}$

Otra compañera que conocía el juego de la güija, comentó: "la güija me dijo lo que ya sabía de mi marido (que andaba con otras),

${ }^{12}$ El hechizo explicaba a los vecinos algo similar a lo que Taussig $(1987,30)$ considera un ambiente o halo protector de la victimización.

${ }^{13}$ La güija es descrita por la enciclopedia británica como un recurso para obtener mensajes del mundo de los espíritus. Se le vincula con sesiones de ocultismo conducidas por un médium. Su nombre deriva de dos palabras oui (si en francés) y ja (si en alemán). En su ritual se pregunta si hay alguna entidad que pueda o quiera manifestarse. Para jugarla se usa un tablero en el que se encuentran grabados y representados todos los caracteres del alfabeto, los números del 0 a 9 y en un lugar preferente el Sí y el No. Sobre la tabla se pone un puntero o flecha que se dirige hacia el número o letras que el médium que conduce el juego quiere identificar como deseos que el espíritu manifiesta a los participantes de la sesión (www.britanica.com.ouija board). Existe una polémica sobre su carácter y consecuencias, dado que existen experiencias muy diversas prácticamente en todo el mundo. Hay casos de víctimas y muertes extrańas relacionadas con el juego de la güija, que se han interpretado como fenómenos paranormales y que incluso han sido documentados en expedientes policíacos que llegan a la conclusión de que no tienen explicación y que no había delito que perseguir, como el llamado "expediente vallecas" que da cuenta de la muerte en circunstancias extrañas de una joven de 18 años (Estefanía Gutiérrez Lázaro) de un barrio de Madrid Espańa (www.cuartomilenio.com). 
pero al preguntarle sobre el número de hijos que tendría me dijo adiós, porque se cree que los espíritus o el demonio saben respetar a los hijos" (Entrevista 3).

Riendo, esta amiga de María, señalaba que las creencias y efectos sobre la salud que puede acarrear el juego de la güija dependen de lo fuerte que sea la mente de la persona. Se afectan más las que tienen mente débil y propensión a la depresión, como probablemente sucedió en el caso de María.

Para varios de los pobladores de El Porvenir, un misterio había quedado escondido entre los costerones ${ }^{14}$ de madera y el techo de cartón consumidos por el fuego. Lo que se presumía era que a María la encerraron en el cuarto para que no pudiera salir. Al consumirse parte de la puerta, ese hueco, le había permitido desplazarse hacia la parte trasera de la casa, donde finalmente la encontraron asfixiada por el fuego.

Cuando en el pueblo estaba el mitote en grande, varios vecinos, conjeturaron que escucharon entre los ruidos del fuego y el claxon de la camioneta, los quejidos de María que repetía una y otra vez: jay Dios porque me hacen esto! ¡Ay Dios porque me hacen esto!

Dos mujeres de mucha confianza y de las vecinas más cercanas, fueron invitadas a rezarle a María, vestirla y prepararla para el velorio. Una de ellas, relata así su intervención:

Cuando llegué me cuide mucho de conservar la calma y no decir nada. De entrada, observé que su madre estaba cubierta con un velo de pies a cabeza, no daba la cara y no quería hablar. Me arrimé a ver el cuerpo que estaba cubierto con una sabana, tenía curiosidad pero me tenía miedo de no aguan-

\footnotetext{
${ }^{14} \mathrm{El}$ costerón es el desecho o tapa irregular de un trozo de madera que se extrae en un aserradero. La tapa que queda una vez moldeada la troza cuadriculada o rectangular, incluye parte de madera y parte de corteza del árbol, de ahí su nombre de costerón. En la costa de Jalisco, las familias más pobres y los migrantes emplean el costerón como pared para circular sus viviendas o como división entre los cuartos. Se entiende que la pared de costerón es provisional y después se substituye por una pared de material, bloque de cemento o ladrillo, aunque las familias más pobres siguen viviendo en casas semiprovisionales. En el caso de los Gutiérrez y otros vecinos, la casa provisional se construía en un lado del lote o en la parte trasera para facilitar levantar la construcción con material más duradero.
} 
tarme y fuera a decir o hacer un gesto descontrolado. No quería ni chistar. Se acercó otra viejita que quería verla, y a ella si, casi la corrieron. Con prudencia levanté un poco la sabana y miré primero la planta de sus pies, estaba bien doradita, como cuando asas mucho un pedazo de carne. Toda ella se veía como si estuviera ahumada. Casi no lograba controlarme, porque empecé a imaginarme lo que habría sufrido María y como fue que sus papas habían tenido valor para hacer eso y permitir que sufriera de esa manera. Para no portarme incorrecta, de plano me volteé para otro lado y deje caer la sabana. De alguna manera, me salvó el señor cura que había llegado y atrajo la atención de la madre y los demás miembros de la familia” (Entrevista 1).

La madre de María era muy cercana al sacerdote que acudía al poblado y ella le servía siempre en la Iglesia. En cuanto llegó al velorio, se sintió aliviada y le preguntó entre sollozos: "verdad padre que cuando usted nos pasó a ver en la noche, todavía mi hija estaba viva". Luego el sacerdote les hizo recomendaciones de que se acercaran a las autoridades y les explicaran de que manera habían ocurrido los hechos y que había sido un accidente lamentable. Al insistirle la madre, el sacerdote quedó de acompañarlos para explicarles a las autoridades. De hecho, su intervención fue de mucha ayuda para que les permitieran levantar y enterrar a su hija.

Aún así, se presentaron los policías y se llevaron al papá de María para que explicara que había sucedido. Cuando iba de salida a subirse a la camioneta de los policías, la señora que había terminado su rezo le espetó: "llévese un buen puño de dinero y aflójeles la lana, quien quite y de esa manera le hagan el paro". A lo que el señor le respondió: "no doña ya me llevó la chingada".

Una de las compañeras de escuela de María, comentó todavía muy conmovida por los hechos, que si ella fuera la autoridad, había refundido en la cárcel tanto al papá como a la mamá. La otra de sus compańeras, recordó que cuando supo del caso algunos días más tarde -porque de momento no estaba en el pueblo-, "nomás de ir pensando en lo que sucedió, se cruzó la carretera sin voltear a ver y casi la atropella un trailer que se fue pite y pite".

Además del padre de María, sus hermanos también tuvieron que comparecer ante la autoridad para explicar lo sucedido. Su explica- 
ción fue coincidente con lo que el sacerdote sugirió del "accidente lamentable”. Para apuntalar esa versión, el sacerdote aprovechó la homilía de la misa del domingo siguiente y le dijo a toda la gente del pueblo: "por favor, ya no comenten acerca de los hechos ocurridos, puesto que tenemos que evitar que la familia chica crezca con rencor" (Entrevista 2).

Para cuidar que no creciera el rencor al marido le quitaron a sus tres hijos, una vez que se juntó a vivir con otra mujer. Le tocó a otra hermana de María sacrificarse a cuidarlos y, por eso, no se ha casado.

A pesar de las previsiones del sacerdote, la muerte de María ha quedado rodeada de un hálito de misterio. Los padres de María se han confiado en el respeto que tenían ganado por los servicios prestados en la iglesia y en el ejido. En la iglesia, la madre tenía una fama bien ganada de mujer muy cumplida con su religión, porque nunca faltaba a las misas y rosarios, además de que apoyaba a los sacerdotes en todas sus iniciativas. En el ejido, el padre tiene el prestigio de ser muy luchador y cooperador.

Con todo y eso, varios ejidatarios propalaron la versión de que los padres habían vendido el alma de María al diablo. Versión que hace recordar lo que Taussig (1987) narra respecto de la rica cultura y explicaciones en torno a la muerte y sus espacios y de como la imaginación social reproduce imágenes del diablo y el bajo mundo. ${ }^{15}$ El dato que parecía corroborar todo era que en poco tiempo ellos lograron reconstruir la casa y hacerse de todos los bienes perdidos, además de adquirir dos camionetas y un tractor equipado.

El PROCESO AGRARIO Y EL MEJORAMIENTO PAULATINO

EN LAS CONDICIONES DE VIDA COTIDIANA DE LOS EJIDATARIOS De El PORVENiR

Hasta los cincuenta del siglo xx, los trabajadores del campo de esa región de la costa acostumbraban trabajar para los dueños de dos grandes haciendas: la de Tomatlán y la de Gargantillo. La riqueza y la tierra estaban repartidas entre 7 familias. Todo el valle que ahora

${ }^{15}$ Michael Taussig 1987, 5. 
conforma más de 30,000 hectáreas comprendidas en un distrito de riego, estaba ocupado con ganadería y lo que se cultivaba eran las tierras bajas y cercanas a los ríos y arroyos. ${ }^{16} \mathrm{El}$ estilo de siembra agrícola se caracterizaba por la práctica del "maíz parido", según la cual el que se contrataba como peón de la hacienda, podía cultivar un pedazo de tierra siempre y cuando entregara como pago dos costales de maíz por cada uno que recibía de semilla.

Los peones estaban en desventaja porque sólo los ricos tenían recuas de mulas para llevar y traer mercancías y hacer las siembras. Hacia fines de los cincuenta, la costa de Jalisco estaba subexplotada y despoblada. Era la zona de mayor extensión territorial de Jalisco, pero apenas aportaba 3.5\% del valor agrícola en la economía estatal, $4.8 \%$ de la ganadería y $0.3 \%$ de la industria. "El desajuste era más notorio, entre la población y los recursos naturales. Además que en la costa era donde [existía] el más grande volumen de materias primas industrializables y la mayor extensión de tierras y agostaderos disponibles". La densidad demográfica promedio era de 5.2 habitantes por kilómetro cuadrado que era la más baja en las cinco regiones en las que entonces se dividía Jalisco. En contraste, la región altos, la densidad era de 35 personas por kilómetro cuadrado (José Rogelio Álvarez 1981, 2)

La iniciación de estudios y trabajos de infraestructura, tendiente al desarrollo de la costa, por parte de los gobiernos estatal y federal, era una consecuencia de la política propuesta tras la segunda guerra mundial, la cual se orientaba a poblar la región y promover la migración como antídoto para evitar posibles invasiones extranjeras, así como estimular el desarrollo productivo. Debido a ello, se dieron migraciones importantes de población, desde fines de los cincuenta. Primero llegó gente de los estados más cercanos: Michoacán, Colima y Nayarit, además de otros municipios de Jalisco. Esto facilitó que entre los migrantes y nativos, se platicara de la posibilidad de emprender luchas agrarias tal como había sucedido en otras partes del país. De esa manera, fue que la gente de El Porvenir se animó a promover la fundación de su nuevo centro de población ejidal, pen-

${ }^{16}$ Cfr. Anónimo, El Porvenir, historia y lucha, RAN (Registro Agrario Nacional), 1985. 
sando que por esa vía se abría la oportunidad de quitarse el yugo que venían soportando por años y se abría la posibilidad de ganarse las tierras que venían trabajando desde varias décadas atrás (Anónimo 1985).

Esa intención se concretó como solicitud en el año de 1963 y en ese intento se inscribieron 42 pobladores nativos, quienes argumentaron la defensa de sus posesiones de muchos años, como motivo para afectar las propiedades de la hacienda del Gargantillo. El problema fue que un poco después, los descendientes de los hacendados entraron en contacto con los dirigentes de la Comunidad Indígena de Tomatlán quienes se habían movido para conseguir el reconocimiento de las posesiones conforme al título virreinal que políticos relacionados con el grupo de los Zuno y gente ligada a la Confederación Nacional Campesina tenían localizado. La comunidad dio albergue como comuneros a varios de los ricos y sus familias, que iban a resultar afectados por los ejidos y de esa forma se empezó a capitalizar económicamente, intercambiando derechos y tierra por aportaciones a la comunidad.

Los intentos del ejido El Porvenir por proteger sus posesiones y obtener más tierra para los solicitantes, se toparon con que los terrenos que ambicionaban estaban en el proyecto agrario de los comuneros de Tomatlán. En el proceso de legalización de la comunidad, se logró atraer a otros campesinos que tenían establecidas huertas de cocoteros y plátano, a quienes se les aseguraba el reconocimiento de sus posesiones siempre y cuando se sumaran a la comunidad y cumplieran con las cuotas y disposiciones de la asamblea. Esto afectó al grupo de fundadores de El Porvenir, que sufrió una primera merma en su grupo inicial, ya sea porque varios se plegaron a la promesa de la comunidad o bien porque querían jugar con las dos posibilidades.

La comunidad inició trámites para invalidar los trabajos que el ejido había gestionado y adoptó una política intimidatoria que amenazaba despojar a los campesinos de la tierra que venían trabajando por ańos si no ingresaban a la comunidad. Una ventaja que tenía la comunidad era que las mismas autoridades comunales solían ser los funcionarios del municipio, a la vez que dirigentes del PRI. De esa 
manera, la comunidad disponía de fuerza pública y mayores recursos para las gestiones. Adicionalmente, seguían incorporando a otros ricos con el pretexto de posesionarlos en la comunidad. En realidad les vendían una tierra a cambio de que aportaran recursos para la gestión. Esa posibilidad estaba vedada y era penada en el código agrario de entonces como práctica corrupta.

Para reforzar al grupo solicitante los promotores del ejido, abrieron la posibilidad de integrar a nuevos solicitantes para la actualización censal presentada en 1964. Eso permitió contar con la participación de 200 posibles derechohabientes, quienes se sumaron a los que permanecieron del grupo fundador. Los nuevos solicitantes de tierra ya no eran sólo de estados vecinos y otros municipios de Jalisco, se acercaron gentes de Guerrero, quienes fueron atraídos por la posibilidad de contar con tierras de riego y obtener empleo en la construcción de grandes obras públicas: la carretera, el montaje de las líneas eléctricas y telefónicas, así como la presa y los canales que conformaron el distrito de Riego 93.

Existen ciertas similitudes en la forma como se integraron al ejido los grupos de solicitantes que lo componen. Unos se ligaron porque conocieron al dirigente en las oficinas de la reforma agraria en México o en la liga de comunidades agrarias de Guadalajara. Otros más, supieron de la posibilidad de conseguir tierras en El Porvenir a través de líderes de ejidos vecinos en formación, pues se daba el caso que entre líderes se pedían que les recomendaran "gente luchona". De esa manera, una vez que se aceptaba a un primer núcleo de solicitantes provenientes de otros estados, éstos recomendaban a otros conocidos, luego éstos se traían a otros y así se iba desplegando la red. Los que ya estaban reconocidos se hacían responsables de que los nuevos solicitantes de su pueblo o estado cumplieran con los acuerdos del ejido y contribuyeran económicamente. Esa fue la forma de operar que permitió mantener la continuidad de la lucha agraria por más de 30 años.

Como el trámite agrario era muy tortuoso (una solicitud de ejido con todas sus etapas legales ya sea que se resolviera positiva o negativamente tardaba en desahogarse al menos 20 años), los líderes no trabajaban igual que cualquier otro campesino. De hecho, aca- 
baban por profesionalizarse. En ese sentido, varios líderes se acostumbraron a vivir de las cuotas de los solicitantes, circunstancia que los llevaba a no apurar demasiado los trámites y a entrar en una lógica clientelar que era fomentada por los funcionarios agrarios quienes exigían de diversas maneras pagos para gestionar y activar el trámite o si no actuaban con cierto tortuguismo que no hacía avanzar un expediente agrario. Con el paso de los años, se dieron nuevas rupturas en el grupo de solicitantes que obligaron a promover nuevos censos y reagrupamientos que prácticamente hicieron empezar de nuevo el trámite. En el caso de El Porvenir, se hicieron 3 censos de solicitantes en 1963, 1975 y en 1990, fecha en la que finalmente se entregaron las tierras.

Los solicitantes evolucionaron ya fuera como hijos de campesinos, comerciantes, trabajadores de diversos oficios y jornaleros. Inicialmente se venían a trabajar para otros ejidatarios de localidades vecinas o lo hacían para quienes conservaban sus posesiones y también con vecinos de la cabecera municipal. La hegemonía de la comunidad, en el distrito de riego y en el municipio, se fundaba en su base territorial, dado que la comunidad de Tomatlán obtendría el reconocimiento legal de un poco más de 40,000 hectáreas. Eso hubiera sido inimaginable en las circunstancias de lucha agraria que por la misma época intentaban comunidades mestizas de otras partes del país y que se conducían en forma más independiente del gobierno.

En el caso de Tomatlán, el reconocimiento legal se logró gracias al apoyo fundamental de un padrino político. Tocó en suerte decretar y ejecutar la resolución presidencial de la comunidad al presidente Luis Echeverría. Quien fungió de padrino, fue su mismo cuñado: Rubén Zuno Arce. ${ }^{17}$ La cantidad de tierra reconocida a la comuni-

\footnotetext{
${ }^{17}$ Rubén Zuno fue diputado federal y funcionario de Conasupo por esos años. La simpatía hacia los comuneros de Tomatlán le venía de tiempo atrás cuando en su época de "aventura revolucionaria" fue primero ocultado y luego ayudado a fugarse por los herreros del pueblo, cuando era perseguido por la policía en una campaña de ensayo revolucionario, realizada por el frente estudiantil al que pertenecía Zuno. Los herreros fueron presidentes de la comunidad y el mayor era también el presidente municipal cuando el ejido de El Porvenir se movilizó para crear su poblado hacia 1976. En los ochenta, Rubén Zuno adquirió notoriedad en la costa dado que se le vinculaba con el narcotráfico y las
} 
dad, en realidad era excesiva, si uno se atiene al criterio del reconocimiento de posesiones que fue el que se siguió y no el de restitución de bienes comunales. Esto dio pie al agrandamiento de la corrupción y el crecimiento del censo que llegó a incluir 3,000 comuneros. Muchos de ellos compraron parcelas en conflicto o que tenían que desmontar.

La actividad principal que desarrollaban como agraristas los miembros de un ejido en formación, era acudir a dos o tres asambleas al año. Estas asambleas se celebraban en el poblado viejo de "La Noria". Lo más importante era la recolección de fondos para pagar las comisiones que servirían para hacer avanzar el expediente agrario. El acuerdo establecido era que una vez que se reconociera al ejido y se le entregaran por parte del gobierno las tierras, se le reconocería a cada solicitante un derecho a una parcela de riego. Mientras el gobierno resolvía, los campesinos seguirían trabajando en sus poblados de origen, donde obtendrían el dinero necesario para cubrir las cuotas y hacer los viajes a El Porvenir cuando se organizaran asambleas. El ritual de las asambleas giraba en torno a los informes de los avances del trámite que las más de las veces eran escasos. Lo espectacular era relatar la entrevista con un alto funcionario y resaltar las promesas que éste les había hecho.

La historia agraria del ejido El Porvenir se distanció de esa rutina lenta y tortuosa, a partir de la incorporación del ejido en la Unión de Ejidos Independientes de la Costa de Jalisco, la cual agrupaba a otros 8 ejidos desde 1972. La unión era asesorada por activistas que participaron en el movimiento estudiantil del 68, venidos de la ciudad de México y de Guadalajara. Como iniciativa para hacer avanzar los trámites ejidales, la unión compró un camión con fondos de todos los grupos, eso se hizo con el fin de que un mayor número de solicitantes y miembros de los ejidos, pudieran acudir a presionar a los funcionarios agrarios de México o Guadalajara.

redes de poder relacionadas con el gobernador Álvarez del Castillo (véase revista Proceso, núm. 627, 12-15). A fines de los ochenta, fue detenido y posteriormente extraditado a Estados Unidos donde enfrenta la condena de cadena perpetua acusado de narcotráfico y de ser el autor intelectual del doble homicidio del agente de la DEA Enrique Camarena y su piloto Alfredo Avelar. 
El trabajar como unión obligaba a compartir las experiencias, mejorar la defensa legal y no conformarse ante las promesas de funcionarios menores. La unión se propuso, en ese sentido, plantear sus asuntos en bloque y acudir al presidente de la república para que se destrabaran los intereses burocráticos y caciquiles que les impedían avanzar. Hasta siete veces, los ejidos de la unión plantearon directamente al presidente Echeverría sus problemas agrarios. El presidente ya los reconocía en sus visitas a distintos estados de la república. En una ocasión, les enviaron un avión hasta la cabecera municipal para hacerse presentes en la ciudad de México en una reunión agraria en la residencia oficial de "Los Pinos".

Una de las primeras movilizaciones de la unión de ejidos, se realizó para sacar de la cárcel al ingeniero de la Reforma Agraria que había realizado trabajos en beneficio de dos de los ejidos miembros. Para ese propósito, los grupos se trasladaron a la cabecera municipal y después de muchos forcejeos sacaron al ingeniero para que continuara sus trabajos. Este hecho, reafirmó la convicción de los dirigentes de la unión, de que había que presionar desde México y mantener la movilización para poder hacer avanzar los trámites. Las entregas definitivas de dos ejidos, reforzaron más esa idea y la desconfianza hacia las autoridades del municipio, la comunidad y el gobierno de Jalisco.

El avance de la unión de ejidos, alertó a los intereses caciquiles que prevalecían en la cabecera municipal. La lógica cerrada de éstos grupos de interés, se refleja en su oposición a que la carretera costera pasara por el pueblo de Tomatlán como inicialmente estaba planeado. Los "caciques de la localidad" convertidos en comuneros y sus aliados, se movilizaron para impedir el paso de la carretera (véase mapa 1, donde se observa la trayectoria de la carretera y la distancia de la cabecera municipal). El argumento usado fue que violentaría la vida pacífica que llevaban y ponía en riesgo sus negocios por la llegada de capitales foráneos que los desplazarían.

Esa carretera es muy importante dado que conecta a Jalisco con otros estados (y se extiende desde Baja California hasta la frontera con Guatemala). El cambio de trazo pedido por los grupos de interés de Tomatlán dejó a la cabecera municipal a 7 kilómetros del entronque a partir del poblado La Cumbre. 

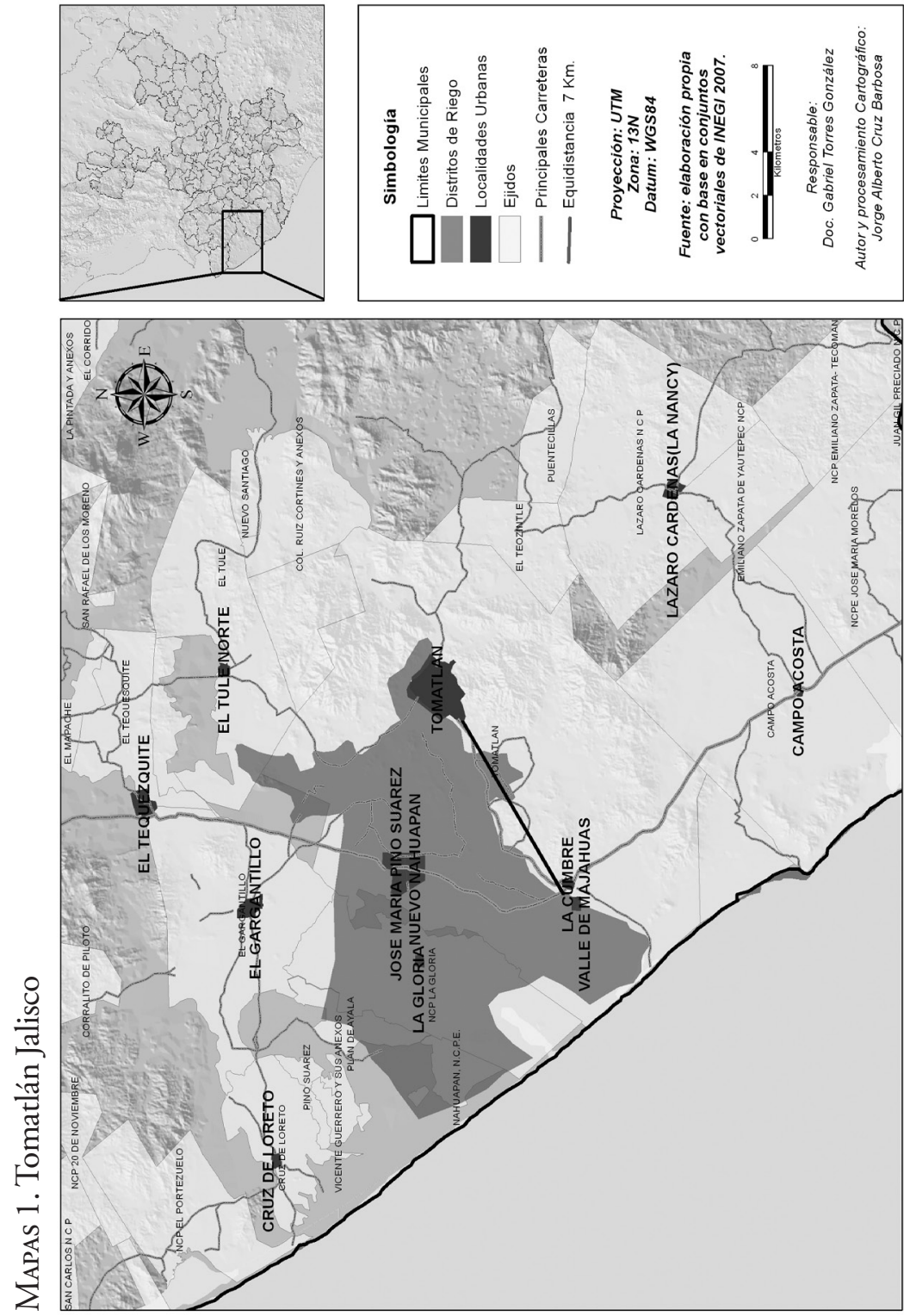
Una acción que desafió más al grupo de interés que dominaba la presidencia municipal y la comunidad indígena fue la fundación del nuevo poblado de El Porvenir precisamente al pie de la carretera costera en terrenos bajo control de la comunidad indígena. Para entonces, ya la comunidad casi había acabado de enterrar su perfil indígena. Aparte de los ricos que se habían incorporado una década antes, se agregaron funcionarios gubernamentales, ingenieros y personal que trabajaba para las compañías constructoras que hacían las obras de infraestructura del distrito de riego y otras complementarias como el tendido de redes eléctricas, canales y vivienda.

La interacción con los nuevos comuneros y otros nuevos ricos integrados a la asamblea de comuneros, trajo consigo un cambio de mentalidad de al menos dos de los viejos caciques de viejo cuño, quienes terminaron por formar alianzas comerciales con los nuevos avecindados y entraron al intercambio de servicios cuando fueron requeridos para vender productos y comercializar con las compañías e instancias de gobierno. De esa manera, se convencieron de que no podían quedarse permanentemente aislados y hasta pusieron un centro comercial a bordo de carretera al lado de El Porvenir. Posteriormente, la comunidad indígena llegó a incluir en su censo a varios americanos que recibieron tierras comunales. Cabe señalar, que no muy lejos de ahí en Puerto Vallarta, los actores Richard Burton y Elizabeth Taylor se convirtieron en ejidatarios del ejido Puerto Vallarta y se dio el caso de que ambos personajes recibieron su título ejidal de manos del secretario de la Reforma Agraria en un acto público hacia mediados de los setenta.

La unión de ejidos, en una reunión de trabajo ante el presidente Echeverría había establecido hacia fines de 1975, entre otros acuerdos, un convenio para intercambiar 38.5 hectáreas con la comunidad indígena que servirían para la formación del nuevo pueblo de El Porvenir. Eso implicaba acercar al ejido en formación con los otros ejidos de la unión, además de un cambio de localización de la sede del ejido desde el viejo pueblo de "La Noria" ubicado 3 kilómetros por brecha hacia adentro, hasta la nueva localidad que se conoce como El Porvenir a orillas de la carretera costera. En la estrategia del ejido, ése era un paso importante que permitiría que 
todos los ingresados que estaban en el último censo actualizado en 1975, tuvieran un lugar de residencia definitivo dentro del ejido.

Como en la práctica las autoridades de la comunidad indígena y el municipio se negaron a cumplir lo acordado, con el apoyo solidario de los otros ejidos de la unión, además de otros grupos venidos de Nayarit, Colima y Michoacán, con los que se habían relacionado en distintos encuentros ante las autoridades agrarias, se llegó a consolidar un respaldo de unas 600 personas que se quedaron a dormir en un campamento improvisado, durante varios días. La descripción que se encuentra en el archivo del RAN habla de un grupo de invasores de la comunidad "como [unos] 100 campesinos provistos de machetes, hachas y barretones que actuaban con mucha prisa midiendo y marcando cada uno de los 160 lotes".

De esa forma, se realizó la toma "pacífica" del terreno incluido en el convenio. El proceso incluyó el trazo de calles y la adjudicación de los lotes para cada familia solicitante. Además del traslado o fincado rápido de tres viviendas provisionales para algunos ejidatarios incapacitados. La primera casa establecida fue la de una mujer viuda que vivía en el viejo poblado de La Noria. Un grupo de 50 gentes sacaron de raíz los troncos que servían de puntales de su antigua casa y conservando la estructura con las vigas y soportes $-\mathrm{y}$ con todo el techo de cartón encima- la cargaron por más de tres kilómetros hasta establecerla en el lote correspondiente a esta viuda en el nuevo poblado. Luego le clavaron el costerón que serviría de pared.

En la fundación de El Porvenir, se siguió la estrategia que había dado resultados previamente y un día antes de la toma pacífica los miembros de la unión hicieron publicar una carta abierta dirigida al presidente de la república. Cabe señalar que esta estrategia de publicar en periódicos de la ciudad de México, era la cuarta vez que la usaban, era eficaz para presionar a los funcionarios agrarios. En este caso, los dirigentes de la unión vieron que la publicación en el Excelsior podría servir para detener el desalojo violento.

En este escrito, la unión de ejidos declaraba que haría cumplir los acuerdos celebrados en Los Pinos empezando por la formación del poblado El Porvenir. 
La respuesta de los comuneros y la presidencia municipal no se hizo esperar. El presidente de la comunidad, quien era al mismo tiempo el presidente municipal, se presentó hasta el lugar acompañado de unos 200 comuneros, una partida militar y otra de la policía municipal. Surgieron momentos de tensión por los dimes y diretes, que se proferían por parte de los grupos apostados en ambos lados de la carretera. La amenaza del desalojo violento estuvo en el aire por más de tres días. Finalmente, se estableció una negociación que sin resolver las cuestiones de fondo, toleraba que los ejidatarios de El Porvenir permanecieran como hasta la fecha en ese lugar, pero negaba toda una serie de posibilidades futuras al ejido como la entrega de la superficie parcelaria y tampoco garantizaba introducir servicios al nuevo poblado, situación que tardaría en regularizarse más de 20 ańos.

De hecho, el municipio y otras instancias gubernamentales bloquearon todo tipo de apoyos para introducir electricidad, agua potable y mejoramiento de vivienda, lo que implicaba hacer más precarias las condiciones de vida de la gente y obligarlos a resolver sus problemas con sus propios recursos, asunto que emprendieron en el caso del agua potable y la electrificación. Era, en ese sentido, muy clara la intención que prevalecía entre las instancias de gobierno municipal, estatal y federal, de evitar que se consolidara la urbanización de El Porvenir y que sirviera de mal ejemplo por lo desafiante que había sido el movimiento fundacional.

En la actualidad, se ha presentado el fenómeno de la alternancia política que ha significado el desmantelamiento y la división del grupo caciquil. En la práctica eso significó que profesionistas independientes (médicos y maestros) le ganaran la partida al PRI a partir de que lograron el apoyo de grupos campesinos en las disputas electorales. Derivado de ello, desde fines de los noventa y hasta el 2003 en dos ocasiones el PRD ocupó la presidencia municipal. En el reciente proceso y el anterior, se ha dado un regreso del PRI encabezado por una maestra del Sindicato de Trabajadores de la Educación. Los cambios en el gobierno del estado y federal, que pasaron a manos del PAN también han influido y hasta alterado las formas de controlar y hacer política en el municipio. Con estos cambios, se 
revirtió la situación de bloqueo político y sus consecuencias económicas para los ejidatarios de El Porvenir.

En el 2009, el contexto del poblado era otro. Ya se habían integrado en un espacio urbanizado más amplio junto con otras 2 comunidades y con el campamento del Distrito de Riego de la Comisión Nacional del Agua. Esto ha facilitado la inclusión para el tendido de redes y servicios públicos establecidos. Sin embargo, aún en la nomenclatura se sigue regateando el reconocimiento oficial a El Porvenir. De hecho, no existen datos desagregados sobre éste poblado. Los censos lo proyectan aglutinado junto con los datos del poblado vecino que es semejante en tamaño a El Porvenir. Eso significa que lo siguen marginando e ignorando en la práctica.

Fue hasta mediados de los ańos noventa, que se entregaron las tierras a los ejidatarios, por cierto, menos de las requeridas para todos los solicitantes reconocidos. Debido a ello, un grupo de 20 solicitantes no reconocidos se posesionaron de otras 200 hectáreas de tierras desocupadas, las cuales vienen cultivando desde 1996 y se ubican al lado de las 650 hectáreas entregadas oficialmente por el gobierno.

Otro grupo de 10 ejidatarios y sus familiares, se integraron a un nuevo poblado agrario que pretende ubicarse a un lado de las tierras de cultivo de los ejidatarios de El Porvenir en terrenos muy cercanos al mar. Este grupo está encabezado por solicitantes venidos desde la Comunidad de Santa Ana Tepetitlán en el municipio de Zapopan en la Zona Conurbada de Guadalajara. Este nuevo grupo de solicitantes agrarios (ejido Mariano Otero) ha establecido vínculos con el Bufete Jurídico Tierra y Libertad y a través de éste se mantienen informados de lo que pasa en el movimiento zapatista y mandan sus saludos como colectivo local al "festival mundial" de la "digna rabia" que enarbola otro mundo, otro camino, abajo y a la izquierda. Además que reciben los boletines y la revista que busca proyectar un tipo de lucha mundializada que "siente que lo que va a pasar [es] la destrucción del capitalismo y la construcción de un mundo mejor" (Cfr. Editorial, revista Rebeldía, año 7, núm. 64, p. 2)

La condición agraria de los ejidatarios de El Porvenir contrasta con la que se observa en la mayoría de ejidos del distrito de riego de Tomatlán, quienes cuentan con 10 ha, para cada ejidatario o comu- 
nero. En el caso de los ejidatarios de El Porvenir, la mayoría sólo recibieron 5 ha. Las tierras que recibieron quedaron a 8 kilómetros del poblado. Diez ejidatarios murieron antes de recibir su tierra, otros 20 migraron a los Estados Unidos aunque siguen regresando para apoyar a su familia en la siembra. De las 120 familias reconocidas en los últimos censos, $80 \%$ de las familias tiene al menos uno de sus miembros en Estados Unidos. Se da el caso de que ellos regresan cada dos y hasta diez ańos, pero se las ingenian en su mayoría para seguir apoyando económicamente a los que se quedan a trabajar en las tierras ejidales.

Respecto de las condiciones de vida de las familias de El Porvenir, se observa que se ha mantenido cierto mejoramiento paulatino. En los datos del conteo 2005, se reportan 225 hogares integrados en las dos poblaciones aglutinadas y otra más pequeña. El nivel de bienestar se muestra con los siguientes datos: cerca de $70 \%$ de la población cuenta con drenaje y servicio sanitario; $65 \%$ tiene refrigerador y televisión; $40 \%$ tiene lavadora y apenas $10 \%$ cuenta con computadora. El porcentaje de los que son dueños de su casa asciende a $75 \%$. Y de los 225 hogares al menos $55 \%$ tienen 2 o más cuartos dado que el número de habitantes por vivienda es de 4.1. Un dato muy interesante es que existen 30 hogares con jefatura femenina. ${ }^{18}$ Esto pareciera contradecir otro dato que establece que en el municipio no se ha reportado ningún caso de divorcio. La población del municipio sigue siendo fundamentalmente católica. Tomatlán cuenta con 28,160 habitantes de un total de 29,862 que dijeron ser católicos en el año 2000. Hay además 414 protestantes, 616 evangélicos y 471 personas sin religión.

Las condiciones de producción agrícola mantienen altibajos dado que no existe plena seguridad por los riesgos propios de la actividad y las desiguales condiciones que enfrentan, además de la in-

\footnotetext{
${ }^{18}$ Estos datos son aproximados, se tuvo que desagregar y calcular en referencia con el dato acumulado que incluye a otras dos localidades aparte de El Porvenir. La población concentrada en esas tres localidades es efectivamente la tercera a nivel municipal $(2,190$ habitantes).Únicamente la cabecera y J. María Morelos que son más antiguos los superan. Por otra parte, no hay datos desglosados en muchos rubros que se siguen manejando en el nivel municipal.
} 
seguridad que se asocia al descontrol en los mercados que imponen ciertos acaparadores y sistemas empresariales ineficientes o expoliadores que de plano roban o se quedan con buena parte del trabajo y la ganancia de los productores locales. No obstante esas dificultades, $50 \%$ de los que trabajan sus tierras han podido ahorrar lo suficiente para reconstruir o hacer casas nuevas que cuentan con todos los servicios. Otros han establecido cultivos como papaya u otros frutales y hortalizas que les significa invertir hasta 100,000 pesos por hectárea y la mayoría lo ha hecho sin contar con crédito oficial, sorteando de diversas formas los escollos; ya sea porque rentan parte de su parcela, ya porque se asocian con otros ejidatarios o con productores de otras partes.

En los inicios de su experiencia como productores agrícolas en las tierras entregadas al ejido, se dedicaron a sembrar ajonjolí y lo hacían como siembra de temporal, dado que todavía no contaban con la posibilidad del riego. Accedieron al riego cuando se organizaron como asociación de producción local apoyada por el gobierno que implementó un sistema de riego por goteo en casi la mitad de las 650 hectáreas entregadas oficialmente. La asociación la formaron 23 socios ejidatarios. El sistema de riego les costó 4 millones de pesos que cubrieron con las primeras cosechas de papaya "maradol" y "ejote largo" cuya venta negociaron con un intermediario chino y con los resultados de esa cosecha prácticamente pagaron el crédito.

En realidad, hay un funcionamiento con estrategias muy mezcladas que los mantiene como productores. Aparte de los granos básicos (el ajonjolí o maíz) que los usan para rotar parte o la totalidad de sus parcelas, lo que permite sobrevivir a la mayoría es incorporar todas las posibilidades de mano de obra y recursos como las remesas y alianzas con otros productores de otros ejidos e intermediarios. Eso les representa que en años buenos, puedan no sólo sobrevivir y no perder, sino obtener ahorros importantes en algunos casos.

En las experiencias que como grupo han enfrentado, cabe diferenciar 3 procesos: 1) el inicial de la producción de ajonjolí que todavía no lo han dejado del todo, pues en la temporada otońo-invierno del 2008 sembraron 100 hectáreas con ese cultivo. El ajonjolí fue el grano que les permitió establecerse en las tierras aun antes de 
que el gobierno se las entregara oficialmente. Llegaron a sembrar hasta 500 hectáreas de temporal durante 5 años seguidos. Con temporal bueno, es decir, cuando caían cuatro tormentas en esa zona tan cercana al mar (tres se consideraban regulares y dos o menos como muy mal año). En el temporal bueno, lograban recuperar $\$ 10,000$ por hectárea (que tomaban como su ganancia una vez cubiertos los fletes y sus días de trabajo). En temporadas malas bajaba a menos de $\$ 4,000$ (Entrevista 5). En la más reciente experiencia les fue bien e incluso se pudieron apoyar con el riego, pero el intermediario que compró, quien es parte de un grupo empresarial que maneja oleaginosas en Guadalajara, no les cumplió lo prometido. Debido a ello perdieron un pago a partir del último precio que subió 30\%. La comunicación con los posesionarios del ejido permitió saber que hubo mejor precio por la semilla. El problema es que no firmaron contrato y el intermediario se ha desistido de la promesa y les adeuda $\$ 1,550,000$ pesos como resultado de las 100 toneladas que le entregaron (Entrevista 5).

La segunda experiencia significativa la iniciaron a partir del año 2000, con el cultivo de papaya. Desde fines de los ochenta, venían haciendo ensayos dado que algunos ejidatarios tenían experiencia desde sus regiones de origen en Colima y Michoacán. El cambio tecnológico que se requiere implementar para mantener una huerta en producción constante durante 7 meses para enfrentar las variables del mercado, aparte de la preparación de la tierra y el uso de pesticidas y fertilizantes, consiste fundamentalmente en el acolchado con tela nylon. En conjunto, esos gastos implican una inversión que varía entre $\$ 80,000$ y hasta $\$ 100,000$ pesos por hectárea, que no todos los ejidatarios pueden afrontar todos los años. Algunos rentan su parcela y por esa vía obtienen $\$ 50,000$ pesos libres al año. Algunos ejidatarios aprovechan para irse al norte o trabajar en otras labores incluyendo la construcción de mejoras en las casas. Cuando les va muy bien con el cultivo sacan entre 60 y 80 toneladas por hectárea. El precio oscila entre 2 y hasta 6 pesos por kilo, comprada la papaya a pie de parcela. "En realidad, no se pierde, sino que se gana poco en el peor de los casos, sobre todo si bajan mucho los precios o te topas con algún intermediario bandido que te roba sin medida” (Entrevista 6). 
La tercera experiencia que han enfrentado recientemente es la de la producción de hortalizas (sandía, ejotes, berenjena, tomate verde y últimamente piña). En esos cultivos, han sido muy variados los resultados. Con el ejote largo iban muy bien, hasta cuando habían sacado 27 tráileres y luego empezó a haber problemas por la diferencia de precios. Aún así trabajaron 8 meses y les alcanzó para pagar lo del crédito del sistema de riego aunque no vieron ningún peso, lo que generó malestar en el ejido y críticas hacia los dirigentes quienes fueron acusados de "quedarse con el dinero de los socios". La sociedad se capitalizó y cuenta con tractores, camionetas y un cobertizo para procesar las cosechas (Entrevista 5). A quienes les ha ido mejor con las hortalizas es a algunos intermediarios, quienes siembran y se especializan ya sea en sandía, tomatillo verde u otros cultivos. Eso se debe a que tienen asegurado su mercado (Entrevista 6).

Estas tres trayectorias que han seguido los ejidatarios como productores nos enseñan dos cosas muy relevantes. 1) Prácticamente las 120 familias que lucharon por la tierra han logrado sacar un recurso suficiente para sobrevivir con el producto de su trabajo en sus parcelas por más pequeńas que sean, eso les ha permitido valorar positivamente la lucha agraria desarrollada. 2) Por otra parte, dado el hecho de que la mayoría partió de condiciones muy semejantes (poco capital y más o menos igual fuerza de trabajo), la explicación de las diferencias en la acumulación económica y en el éxito productivo obedece a condiciones multifactoriales y a su capacidad de socialización y conexión en redes. No siempre el que tiene más tierra, fuerza de trabajo o capital es el más exitoso. Al respecto, no existe un patrón homogéneo que nos explique cómo se han construido esos éxitos relativos. Incluso ha habido éxitos que sólo han durado 3 y hasta 5 ańos y luego fracasan. Hay casos de ejidatarios que hasta se tienen que ir por las deudas y malos tratos con otros ejidatarios.

Uno de ellos, quien es repatriado de California desde 1980, operó en un nivel que ninguno otro había alcanzado. Se convirtió en empresario y controlaba una empacadora de frutas y legumbres, que al menos enviaba diariamente un camión o tráiler cargado de fruta a las ciudades importantes de México y los Estados Unidos. El círculo de trabajo de este empresario local, alcanzaba más de las 
200 hectáreas de cultivos arrendados, comprados y propios. En ocasiones, se especializaba en papaya y otros frutales, pero también manejaba hortalizas, granos básicos y otros negocios como un pequeño hotel, comercio y ganado. En las cuadrillas de trabajo que este ejidatario tenía organizadas en todo el año trabajaban unos 20 jóvenes de El Porvenir incluidas varias mujeres.

Su buena estrella, declinó una vez que se volvió más repetitiva la práctica de que entregaba cuentas parciales. Normalmente descontaba de un viaje de papaya hasta $20 \%$ del producto bajo el pretexto de mala calidad y nunca regresaba nada que lo probara, esa práctica hacia recordar los días del maíz parido. Además que se endeudó fuertemente con un prestamista que se decía lavaba dinero y le prestaba en dólares. Asfixiado por las deudas, de plano se tuvo que ir de la región. Ahora opera en Tijuana y algunas veces se le ve por acá comprando cosechas, pero ahora siempre viene con guardaespaldas (Entrevista 6).

Otro caso muy diferente es el de una mujer que organizaba siembras en el ejido. Es el único caso de una mujer que ha emprendido la empresa de organizar siembras, más allá de su propia parcela en el ejido y en toda la región. Ella como migrante, había acumulado diversas experiencias a partir de que se separó y vivió como mujer sola. De hecho, era muy admirada por su arrojo por otras mujeres que la estimaban y se reunían a divertirse con ella los fines de semana. Cuando tuvo que migrar no le importó que la juzgaran mal por promover su divorcio e irse sola al norte a trabajar en el campo, rentar tierras y organizar varios cultivos.

Su regreso fue motivado por el cierre de la frontera y el endurecimiento de la política migratoria por parte de Estados Unidos. Debido a ello, se tuvo que regresar en su condición de mujer divorciada, a El Porvenir. Ella ha sabido sacar provecho a sus experiencias en Estados Unidos y se ha atrevido a organizar cultivos en tierras de El Porvenir y también ofrecer oportunidades de empleo a otras mujeres en las 10 y hasta 30 hectáreas que logró sembrar en dos años seguidos. Contó para ese propósito, con el apoyo de las remesas de sus hijos y los ahorros que logró conservar a su paso como trabajadora en varias entidades americanas. 
Al final, le fue mal y se tuvo que regresar otra vez a Estados Unidos. En la explicación que ofreció uno de los ejidatarios que trabajó con ella y veía con simpatía sus esfuerzos "porque le echaba muchas ganas", le achacaba que no supo agarrar consejos y se rodeó de gente que la llevó al fracaso, además de que "no supo controlar sus gastos y sufrió una fuerte merma de parte del otro empresario local quien era su compadre y le quedó a deber mucho dinero cuando se fue huyendo a Tijuana" (Entrevista 6).

El caso de los Gutiérrez es también muy significativo, porque les ha ido muy bien. Ellos se han dedicado a producir papaya y ajonjolí y no han perdido en los casi 10 años seguidos que llevan cultivando. Como lo explicaron las compañeras de escuela de María, su éxito ha sido porque siguen trabajando juntos el padre y los hermanos. A lo mejor ahora que se separen (porque ya viven aparte los hermanos que se casaron recientemente), van a disminuir las utilidades y se va a notar en la empresa familiar (Entrevista 4).

El caso de otros ejidatarios que recientemente vendieron sus parcelas para retirarse a los poblados de donde son originarios, abren dos ventanas que permiten explorar el futuro y visualizar la penetración al interior del ejido de intereses hacia una mayor capitalización y la substitución o conexión con factores externos que apuntan a predominar. Dos ejidatarios pudieron afrontar su retiro productivo vendiendo sus tierras y obteniendo una cantidad cercana al millón de pesos por sus parcelas que les permitirá sobrevivir en mejores condiciones que las de un simple trabajador agrícola. Su retiro se debe en parte a la edad y en parte a las deudas no liquidadas, que derivaron de la falta de pago en sus cosechas de papaya por parte del "empresario" local. Esto da idea de cómo podrá ser el panorama de quienes se retiran de la actividad agrícola en El Porvenir. La otra ventana permite ver el perfil de los nuevos ejidatarios que los substituyen. Uno es un ejidatario joven de otro ejido y quien tiene varias parcelas y cuenta muchos contactos para vender hortalizas, éste se apunta para convertirse en un nuevo rico. El otro caso es parecido, se trata de otro productor que compró otra parcela y se ha dedicado a rentar tierras y está especializado en la producción de sandía. 


\section{El Porvenir y la hummerización: Desorden local, DIVERSIDAD CULTURAL Y DOMINACIÓN POLICÉNTRICA}

Las viñetas de narrativa etnográfica describieron el acontecer histórico de un grupo socialmente invisible, si es que se le considera desde el punto de vista de su relevancia regional, nacional e internacional. El ejido El Porvenir ni siquiera existía en las estadísticas oficiales. Por su combatividad y lucha agraria había sido sacado del mapa. Sin embargo, por las experiencias acumuladas, sus pobladores se convirtieron en protagonistas y observadores muy agudos del desarrollo capitalista y los procesos políticos de la región y del país.

El contexto de "desorden y anarquía local" en que se inscribe la cotidianidad de El Porvenir, se ha reflejado desde el origen mismo de la comunidad, la cual se formó a contrapelo de los intereses de los gobiernos municipal y estatal y de la comunidad indígena. Esa imagen predomina en el estilo de interrelaciones principalmente en los escasos acuerdos institucionales locales y en la transformación o negociación de las formas de dominación relacionadas con iniciativas foráneas.

El poblado en sí amalgama las experiencias de al menos 8 grupos de migrantes que comparten historias y antecedentes culturales muy diversos, en cuanto a sus tradiciones agrarias, los estilos de hacer agricultura y los repertorios culturales en sus costumbres familiares incluyendo su orientación religiosa y de género. Pero, por más peculiar u original que podamos pintar a esas experiencias de vida concretas, su mayor significación depende de su inserción en comunidades que se insertan de diversas maneras en el nuevo mundo de redes sociales interconectadas descrito por Castells (1999 370, tomo III) y que es propio del fin de milenio pasado. La manera como usan las tecnologías y se inscriben como consumidores de los distintos mercados, los relacionan con grupos sociales sin fronteras fijas que interconectan esa pequeña localidad, por más aislada que la veamos, con distintas entidades globales.

Por tratarse de pobladores constituidos por grupos de migrantes, de identidad mestiza o interétnica, sus testimonios e historias de vida reflejan experiencias en las que se mezclan representaciones culturales mixtas junto con y al lado de las de nativos tomatlenses. En 
sus testimonios predominan distintas expresiones de diversidad cultural que no son tomadas en cuenta en las políticas públicas gubernamentales hacia el campo. No obstante, esa riqueza de costumbres y acervos de conocimiento les ha permitido enfrentar con éxito el bloqueo político que los ha afectado por más de 20 años y que los constituye como zona de frontera frente a otros grupos ya asentados en la región.

En efecto, la narrativa histórico-estructural muestra cómo se proyectan los efectos de la crisis de los modelos de desarrollo estatista y capitalista en la trayectoria del grupo ejidal y en toda la región costera. Las grandes inversiones e iniciativas gubernamentales no han logrado integrar completamente a estos grupos que mantienen sus dinámicas de movilidad itinerante hacia sus pueblos de origen y hacia los campos de cultivo o ciudades estadunidenses donde se originan los recursos que les garantizan la sobrevivencia y les permiten intentar hacer economías de escala, porque no han podido confiar su suerte a lo que les depara el esquema de desarrollo rural integral promovido por el gobierno mexicano en distintas épocas.

Ni duda cabe que varias entidades locales y foráneas les han pasado por encima en muchos sentidos y han condicionado sus posibilidades de crecimiento económico e incluso no han respetado su dignidad, sus derechos humanos y sus distintas expresiones identitarias. Pero también ha sucedido que los intereses capitalistas, aunque los han internalizado de distintas maneras, dado que han aprendido a funcionar con ellos, tampoco se han podido consolidar porque han actuado mediante intermediarios que capitalizan y manipulan y que en realidad son quienes se llevan la plusvalía y descapitalizan la región, sin que lleguen a arraigarse completamente y tenderán a ser substituidos por actores emergentes en distintas circunstancias. De hecho, los ciclos de capitalización interna y externa, que pasan del cacique al intermediario y al empresario o contratista con ciertas involuciones, se generan a partir de la sobreexplotación de los recursos naturales y de distintas formas de robo ya sea directo desde círculos externos o mediante conductas internalizadas como la del empresario local, quien a fin de cuentas sucumbió presionado desde afuera y desde adentro. 
En las distintas fases del ejido en formación, se observa una flexibilidad organizativa guiada por la capacidad de sobrevivir de los solicitantes, quienes luego devienen en ejidatarios y, de esa manera, logran hacer frente a las condiciones de bloqueo político y escasez de recursos que imponen agentes que forman parte de un Estado (neoimperial) que ha recurrido al ejército para intentar frenar la violencia, pero que en muchos sentidos sigue siendo un estado ausente y fallido. Por otra parte, la relevancia del ejido como entidad productora se logra hasta que logran establecerse y convertirse en trabajadores y propietarios de la tierra superando la inicial consigna zapatista de "la tierra para quien la trabaja", con la de "la tierra para quien sepa sacarle jugo y sobrevivir de ella”. Entonces eso se da cuando se logran cuajar diversas formas de inserción en los flujos de economía globalizada. De hecho, a pesar de producir en un área alejada de caminos y muy cercana al mar, los intermediarios y agentes capitalistas los buscan porque "poseen las mejores tierras o porque conocen de su capacidad como cultivadores que ofrecen buenos productos y están dispuestos a aprender nuevas técnicas" (Entrevista 5).

El cambio en los procesos productivos, se contextualiza como fusiones y rutinas de trabajo que transforman a unos ejidatarios pobres y aislados, quienes de pronto se relacionan con aliados que los lanzan a las rutas de la mundialización económica cuando exportan su producción local. Además que se las ingenian para mantener abiertas sus rutas de migración; de intercambio de remesas y otras mercancías; de posibilidades productivas e inversiones locales, por una parte y, por otra, se dinamizan creando nichos de mercado que saben negociar y reciclar con los intereses externos y los asentados en la comunidad indígena que poco a poco supo apreciarlos como consumidores.

La inserción en el mercado para sus productos, inicialmente buscada en forma ingenua, luego se reflejará como fatal intercambio desigual que favorece a los intereses de las empresas translocales u otros intermediarios asentados temporal o definitivamente en la región. La "ingenuidad" de la primera inserción se transformó con el tiempo en desengaño. Eso refleja que no se tenían previstas todas las consecuencias de trabajar la tierra y ser propietarios en una zona de desarrollo capitalista. De hecho, no bastaba intentar evitar el aislacionismo. 
En el proceso político, la unión y defensa en bloque de los ejidos y el aprendizaje que lleva a superar un nivel de control burocrático, es otra de las pautas que marcan los forcejeos contradictorios entre distintas instancias con poder y que culminan con una cierta desestabilización del proceso democrático que ha obligado a replantear los esfuerzos de dominación capitalista hacia lo policéntrico. En este sentido, los ejidatarios se ganan el respeto y se vuelven votantes importantes pero no definitorios, para inclinar la balanza en el refuego de intereses electorales locales.

En el estilo político y las formas de hacer de los agentes gubernamentales se observa el fracaso y declinamiento del esquema de poder centralizado y autoritario (que se imponía desde la jefatura del distrito de riego o la presidencia municipal). En realidad, sucede que en la región se constituyen varios centros de poder con estilos diferentes. De esa forma, se llega a una alternancia que no profundiza el cambio sociopolítico, sólo lo reinicia y lo deja expuesto a la involución y a la frustración que producen alternativas ambigüas que confunden intereses y mezclan estilos de control político propios del cacicazgo con las dinámicas flexibles de las estrategias de sobrevivencia y los liderazgos emergentes que influyen en los grupos que se aprovechan de la cobertura partidista.

Pero más allá de un libreto estructural cumplido al pie de la letra, lo que se nos refleja en las viñetas son los vericuetos complicados de los acomodos e interacciones cotidianas y los arreglos institucionales logrados en medio del estira y afloja entre esas "tribus localizadas" que aparecen actuando en El Porvenir en circunstancias que reflejan condiciones muy diferentes a las de la revolución y resistencia de las multitudes previstas por Hardt y Negri por más que entre estos ejidatarios haya surgido y se mantenga actualizada la conexión con el festival mundial de la digna rabia zapatista, el cual caracteriza a las luchas positivas acumulativas que traspasan fronteras.

Es sorprendente lo incierto de su devenir histórico y las complejas mezclas que prevalecen en su ideario. En un poblado fundado en medio de la solidaridad entre agraristas de varios estados que fueron capaces de enfrentar al cacicazgo y que mantuvieron su viabilidad urbana mediante esfuerzos compartidos entre vecinos durante ańos, 
se tuvo que optar por la ignorancia como estrategia para preservar el pacto entre vecinos, pero a costa de tolerar una situación extrema de exclusión, que es vista incluso, como criminal y diabólica por lo que representa en términos de violación a los derechos humanos.

En el caso de la muerte de María, los ejecutores individuales fueron exculpados por la entidad que norma las conciencias y dicta las normas morales. $\mathrm{Al}$ respecto, es pertinente asociar lo que hoy en día sucede en Jalisco y otras partes del país con la ley antiaborto. Pareciera como si los anhelos y razones de la preocupada madre de María fueran el motor que anima la protesta de muchas heroínas vestidas de blanco. Ese tipo de heroísmo promovido desde el vaticano se enfoca en mujeres a quienes se exalta como fervientes defensoras de la vida, la moral y las buenas costumbres. Esa posición política, que reanima la inquisición, sirve de motivación para cerrar posibilidades a un gobierno o políticas progresistas hacia las mujeres. Eso, además pareciera justificar el castigo extremo hacia una "mala vida" que si acaso ha incurrido en un "pecado circunstancial" como ha sido el caso de María. De esa manera, las mujeres proabortistas son condenadas en el imaginario colectivo, con todo y que se da una gran desproporción que no justifica los medios empleados, ni tampoco repara en el significado de la exclusión de esas minorías y el atentado contra sus vidas. Desde esta perspectiva, la muerte de María puede verse como estructural y socialmente dictada y no como una circunstancial salida ante las ocasionales admoniciones de un sacerdote (cardenal o papa) frente al pueblo.

En estos últimos años, se ha intensificado en todo México el fenómeno de la violencia (que ha significado decenas de miles de muertes, secuestros y muchos otros actos violentos). Las muertes violentas de cientos de mujeres en el norte del país, casi se han constituido como un fenómeno de conducta cotidiana sobre todo en Ciudad Juárez, Tijuana, Sonora y Tamaulipas. Este fenómeno refleja una exclusión estructural hacia las mujeres que se da más precisamente en las zonas del país, donde se supone que hay más riqueza y empleo y debieran presumirse mejores posibilidades para las mujeres. El caso de María es apenas un bosquejo incipiente de una condición que pudiera agravarse y que definitivamente refleja otros matices de esa paradisiaca 
región costera. Como quiera que sea, la exclusión de María corrobora otras dimensiones salvajes de la lógica capitalista y del mercado, que no ofrece oportunidades, ni muestra mayor interés por mujeres jóvenes deseosas de trabajar, así como también apunta a la incapacidad de los agentes gubernamentales, comerciales y eclesiales, para forjar una sociedad equilibrada y autosustentable que articule efectivamente producción, empleo y consumo y con ello abra más oportunidades a las mujeres. Además, el hecho por sí mismo, habla de lo grotesco que resultan ser las representaciones de doble moral que pudieran considerarse como propias de elites sociales y sectores más urbanizados, pero que también se presentan en sociedades rurales.

En el lenguaje y los códigos de las "tribus localizadas", hay muchos ecos de las voces, valores y hasta disparates propios de las grandes instituciones, las cuáles por años han tratado, pero no han logrado imponer un control de la conducta social que regula los cuerpos de la gente. En ese sentido, se puede ahondar en los significados de "juegos misteriosos" como la "güija" visto como circunstancia global que relaciona la posesión diabólica y un eventual castigo divino. En este caso, se corrobora que el mito de la modernidad no se impone a la realidad, ni significa el triunfo del progreso sobre el atraso que descarta todo tipo de involución. En cierto modo, se registra una reemergencia bajo otras circunstancias de la era de la inquisición con todo y hoguera, la cual no pudo ser sepultada definitivamente por la inercia de la modernidad. También hay una especie de reencarnación de un autoritarismo extraterritorial en la que convergen los sacerdotes, brujos y curanderos junto con los políticos que añoran superpoderes.

Los únicos hummer que han sido vistos por muchos días rodando en las calles de El Porvenir, son propiedad de los intermediarios y de quienes se rumora son narcos que operan como exitosos mercaderes de productos agrícolas. Un caso muy significativo es el de un ejidatario de la sierra "que de pronto se enriqueció" y anda en uno de esos hummers más lujosos que cuestan más de 800,000 pesos, que le sirve para pasear a la muchacha más guapa de otro pequeño poblado.

Otros dos hummer que se han visto se les asocia con las operaciones encubiertas de las bandas que esperan cargamentos de drogas 
venidos del mar. A los posesionarios próximos al ejido de El Porvenir, les ha tocado observar-cuando se han quedado a cuidar sus cosechas por la noche muy cerca de la playa- la manera como se proyectaron intempestivamente dos o tres luces de bengala que sirven de señal (bien entrada la noche), a las cuáles se sigue un intercambio de señales con lámparas. En esas rápidas incursiones se da una rutina: "las lanchas son arrastradas a la arena con mucha rapidez por 3 o 4 personas. Luego, las sepultan en la arena con un trascavo, mientras que las cargas son transportadas a otro destino en una veloz hummer que al apresurar su maniobra se mete hasta mar adentro, sin hacer caso del oleaje". ${ }^{19}$

Las formas de concretar una estrategia económica exitosa entre los ejidatarios no se corresponden con las reglas capitalistas ortodoxas y no dependen de un ejercicio simple de ganar o perder en la línea de un determinismo económico. Hasta ahora, se ha dado un balance favorable que valora los esfuerzos para la sobrevivencia y hace viable a su ejido. Aun en el caso de los que se retiran, su lucha agraria, su trabajo y su tierra les han permitido gozar de una pensión relativamente suficiente. En ese ámbito, también las mujeres productoras han encontrado espacio para encabezar proyectos, como lo muestra el caso de la mujer divorciada que regresa y ha sido exitosa en su nivel. Empero, hay una capitalización e identidad productiva heterogénea e incompleta (Friedmann 1994). El "éxito" económico se ha logrado sin reglas fijas mezclando los factores de confianza, formas de ser y hacer y estrategia de negocio. No es que no haya confrontaciones de clase o intereses difíciles de compatibilizar, éstos existen, pero se agrupan y se resuelven conforme acuerdos informales que se pactan como contratos temporales.

En un futuro inmediato, se visualiza que seguirá prevaleciendo una constante adecuación de las condiciones de la localidad en las que el préstamo de favores, los trueques diversos a cambio de empleo y de productos, por lo menos han impedido que la diferenciación social se vuelva abismal, dado que esos acuerdos substituyen o complementan lo que las estrategias financieras (los préstamos de

\footnotetext{
${ }^{19}$ Narrativa de uno de los miembros del grupo solicitante del ejido López Cotilla.
} 
los bancos, cajas de ahorro, prestamistas y los apoyos de instancias gubernamentales), así como el comercio justo de productos del campo no dan o hacen más incierto. En ese sentido, las preocupaciones cotidianas de estos ejidatarios seguirán muy desentendidas del poder neoimperial y sus pretensiones de dominación de cualquier rincón del mundo.

\section{Referencias Documentales}

Anónimo, El Porvenir, historia y lucha, Registro Agrario Nacional, 1985.

Álvarez, José Rogelio, "La Comisión de Planeación de la Costa de Jalisco en el Período 1953-1959”, Ponencia al primer Encuentro de Investigación Jalisciense, Panel: Economía y Sociedad, El Colegio de Jalisco, 1981.

Appadurai, Arjun, Modernity at Large: Cultural Dimensions of Globalization, Minneapolis, Londres, University of Minnesota Press, 1998.

Castells, Manuel, La era de la información: economía, sociedad y cultura, tomo III, Fin de milenio, México, Siglo XXI editores, 1999.

Gupta Akhil y James Ferguson, Beyond "Culture": Space, Identity and the Politics of Difference in Culture, Power \& Place: Explorations in Critical Anthropology, Durham y Londres, Duke University Press, 1999.

Friedmann, Jonathan, Cultural Identity \& Global Process, Londres, Sage Pubs., 1994.

Hardt Michael y Antonio Negri, Empire, Cambridge, Londres, Harvard University Press, 2000.

Hardt Michael y Antonio Negri, Multitude: War and Democracy in the Age of Empire, Londres, Penguin Books, 2005.

Harvey, David, The New Imperialism, Oxford, Oxford University Press, 2003.

Kapferer, Bruce, "Ensayo-reseña: Fundación e Imperio: Una Consideración de Empire de Michael Hardt y Antonio Negri”, en Relaciones. Estudios de Historia y Sociedad, núm. 90, Zamora, El Colegio de Michoacán, 2002, 259-276. 
Lenin, Vladimir I., El imperialismo fase superior del capitalismo, Moscú, Editorial Progreso, 1920.

Maffesoli, Michel, El tiempo de las tribus: el ocaso del individualismo en las sociedades posmodernas, México, Siglo XXI editores, 2004.

Ritzer, George, The Macdonalization of Society, Thousands Oaks, Pine Forge, 1996.

Rosaldo, Renato, Cultura y verdad: nueva propuesta de análisis social, México, Grijalbo, Conaculta, 1991.

Taussig, Michael, Shamanism, Colonialism and the Wild Man: A Study in Terror and Healing, Chicago y Londres, The University of Chicago Press, 1987.

Williams, Raymond, La larga revolución, Traducción al español Horacio Pons, Buenos Aires, Nueva Visión, 2003.

Willis, Paul, The Etnhographic Imagination, Cambridge, Polity press, 2000.

Entrevista 1 con señora de confianza Familia Gutiérrez, marzo 2009.

Entrevista 2 con compañera de Escuela de María, marzo 2009.

Entrevista 3 con compañera de Escuela de María, marzo 2009.

Entrevista 4 con hermana de la compañera de escuela de María, marzo 2009.

Entrevista 5 con el comisariado ejidal de El Porvenir, marzo 2009.

Entrevista 6 con ejidatario de El Porvenir, marzo 2009.

FeCHA DE RECEPCIÓN DEL ARTículo: 20 de enero de 2010

FECHA DE ACEPTACIÓN Y RECEPCiÓn DE LA VERSIÓN FINAL: 22 de noviembre de 2011 